Document downloaded from:

http://hdl.handle.net/10251/132134

This paper must be cited as:

Salas, J.; Yepes, V. (2018). A discursive, many-objective approach for selecting moreevolved urban vulnerability assessment models. Journal of Cleaner Production. 176:12311244. https://doi.org/10.1016/j.jclepro.2017.11.249

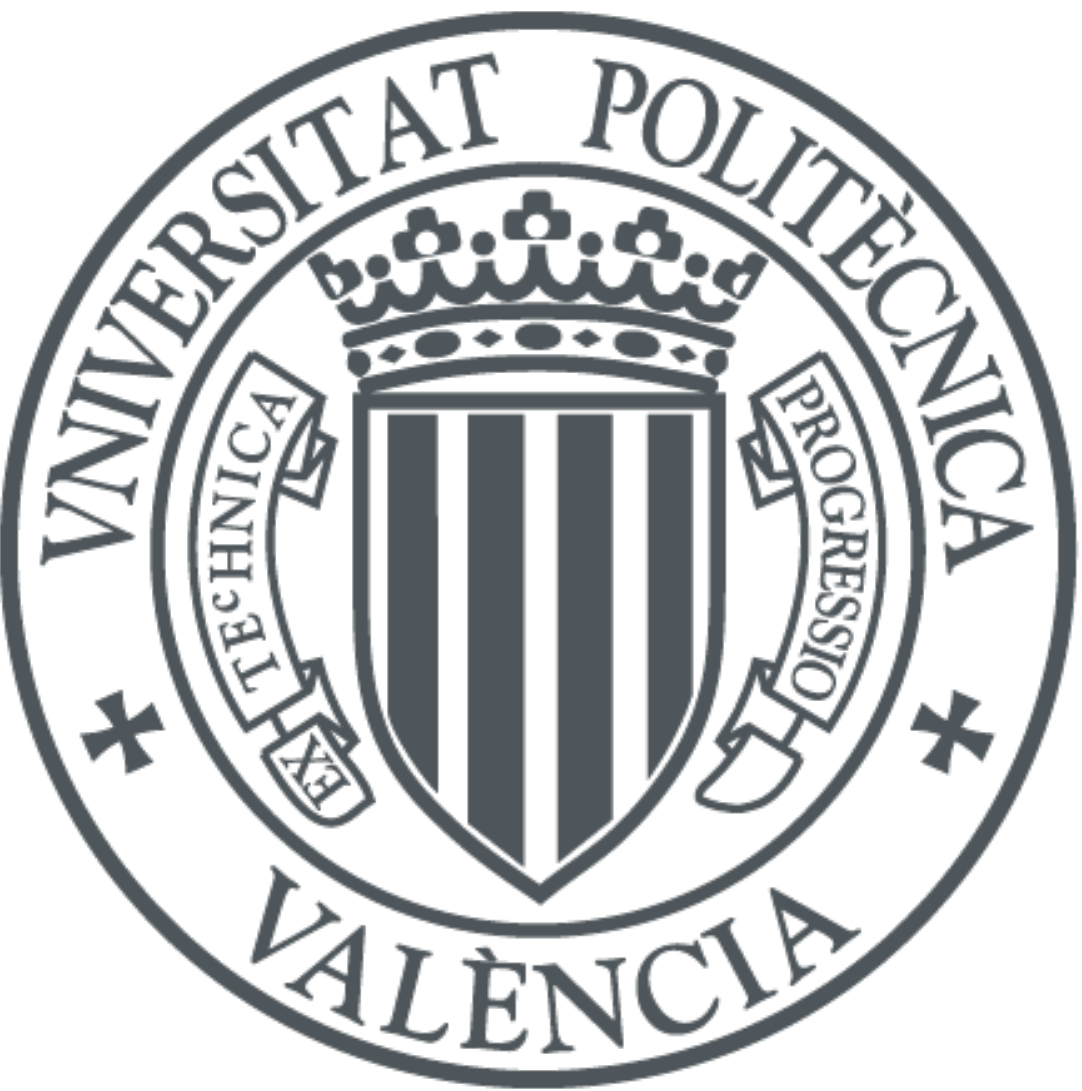

The final publication is available at

https://doi.org/10.1016/j.jclepro.2017.11.249

Copyright Elsevier

Additional Information 


\title{
A discursive, many-objective approach for selecting more- evolved urban vulnerability assessment models
}

\author{
Jorge Salas $^{1}$ \\ Víctor Yepes ${ }^{2}$
}

\begin{abstract}
The development of more-evolved urban vulnerability assessment (UVA) models has become an increasingly important issue for both policy agendas and academia. Several requirements have already been set for this goal; they should be pursued simultaneously. However, methods with such integration are yet to be developed. The present paper addresses this integration via a discursive process in which interactions between decision makers and the method contribute to the selection of a model fulfilling these requirements. That model yields a UVA built upon both qualitative information and quantitative data from indicators selected for the neighbourhood, city, province, region and country political-administrative scales. The characteristics demanded are encoded both into the UVA assessment model and in the optimization and control modules governing the process. While the optimization produces compromise solutions, the control module supervises the process, provides dynamic control and enables the interactions. Interactions are informed with knowledge derived from the cognitive approach entailed by the method and afford a better understanding of the process dynamics. We conclude that the goodness of fit and time dynamics objectives are aligned. Therefore, UVA methods performing well for these objectives are available, although at the expense of medium to poor preferences and robustness of performance.
\end{abstract}

Keywords: urban vulnerability assessment, discursive approach, many-objective optimization; cognitive approach.

\footnotetext{
${ }^{1}$ Graduate Research Assistant, School of Civil Engineering, Universitat Politècnica de València, 46022 Valencia, Spain. Corresponding author. Phone +34963879563; fax: +34963877569; e-mail: jorsaher@doctor.upv.es

${ }^{2}$ Professor, ICITECH, Universitat Politècnica de València, 46022 Valencia, Spain. Phone +34963879563; fax: +34963877569; e-mail: vyepesp@cst.upv.es 


\section{Introduction}

Urban vulnerability (UV) in general and its adaptive component in particular have become key issues for urban strategic planning (USP) (Rigillo \& Cervelli, 2014) with the aim of achieving sustainable development (Malekpour et al., 2015) and coping with climate change (McCarthy, 2001; Turner et al., 2003; Adger, 2006; Chang \& Huang, 2015). Specifically, improvements of adaptive governance and strategic planning in the context of climate change and socio-economic transformation are demanded (Birkmann et al., 2014). As a consequence, methods that assess vulnerability are increasingly being developed for countries around the world (Fekete, 2009).

The IPCC Assessment Report (McCarthy et al., 2001) defines vulnerability as follows: "The degree to which a system (entity) is susceptible to, or unable to cope with, adverse effects of climate change, including climate variability and extremes. Vulnerability is a function of the character, magnitude and rate of climate variation to which a system is exposed, its sensitivity and its adaptive capacity."

This concept is, to a high degree, negatively correlated with that of resilience (Adger, 2006), whose improvement is in turn considered essential by USP for the sake of urban sustainability.

Nevertheless, there are many other definitions that challenge current thinking, to the extent that it is necessary to perform research specifically aimed at conceptual clarification (Füssel \& Klein, 2006; Wolf et al., 2013), which exceeds the scope of this study. A few aspects, however, are beyond question, the first being that vulnerability should be assessed with regard to not only its current state alone but also its future risk, and the other being the attributes demanded by the research community for the assessment of this concept.

Concerning the first aspect, several authors have pointed out the dynamic character of vulnerability over time and that, in consequence, along with the current state of vulnerability, the risk of becoming (more) vulnerable also needs to be measured (Adger, 2006; Birkmann et al, 2014; Füssel, 2007; Nahiduzzaman et al., 2015). Therefore, "the ability to monitor and anticipate vulnerability would be a public good for all potentially affected places and systems" (Stern et al., 2013, pg. 609) and can help solve resourceallocation problems (King \& Blackmore, 2013; Nahiduzzaman et al., 2015; Rigillo \& Cervelli, 2014) by providing prioritization guidelines. According to Brooks (2003), a quantitative assessment of risk is desirable in order to develop integrated vulnerability assessment models. However, there are not many examples of how to conduct such assessments on a quantitative footing (Birkmann et al., 2014; Lummen et al., 2014). In 
the particular case of UVA, models quantitatively assessing risk are yet to be developed. As to the second aspect of vulnerability, the attributes demanded are robustness as a way to cope with uncertainty (Dominguez et al., 2011; Hall et al., 2012; Malekpour et al., 2015), use of cognitive approaches (Mustafa et al., 2011; Yepes et al., 2015; Pamungkas et al., 2014), a better understanding of UV dynamics over time and politicaladministrative scales (Adger, 2006; Birkmann et al., 2014; Liu el al., 2010; Pamungkas et al., 2014), and having a strategic, multi-objective capacity to avoid eventual tunnelling effects and to improve the system's adaptive capacity (Munda, 2004). Also, it is necessary to account for the subjective and complex nature of urban vulnerability (Adger, 2006). Previous works have pointed out the need to develop methods that integrate most of these research requirements in order to advance the field of UVA assessment methods towards the discursive stage in urban strategic planning. This stage represents the latest trend in this field (Dominguez et al., 2011; Malekpour et al., 2015) and conveys the adaptive policy capacity demanded to face system's vulnerability (Adger, 2006; Fussell \& Klein, 2006). Although works dealing with these requirements separately have already been developed, a UVA method integrating them all is still lacking.

On the other hand, in spite of the amount of works pointing out the importance of the dynamic nature of urban vulnerability across its multiple scales (Adger, 2006; Giezen et al., 2015; Lundqvist, 2016; Pemberton \& Searle, 2016; Romero-Lankao \& Qin, 2014; Toubin et al., 2015), there is still a gap in the development of quantitative models for the assessment of UV that take into account the multiple political-administrative scales in which entities are contextualized.

The integration of methods addressing the research requirements may be achieved by means of multi-objective optimization modelling methods that encode the research requirements in objectives such as robustness of the model (as opposed to its sensitivity) or goodness of fit (Boada et al., 2016). These objectives work as the attributes that define the behaviour of the model.

Optimization modelling has been previously employed to deal with problems concerning urban management. Among those techniques, genetic algorithms are robust and efficient heuristic algorithms for solving problems defined by urban vulnerability assessment (UVA) methods and for looking for solutions in large, complex, non-linear and littleunderstood search spaces. This method has already been proposed for addressing unstructured urban issues and multi-objective land-use planning problems, as well as in the development of more sustainable strategies (Martí et al., 2016; Mousavi-Avval et al., 
2017; Zhang \& Chiong, 2016).

The objective of this paper is to present a new method, embodying the attributes demanded for UVA, that is capable of selecting an optimized urban vulnerability assessment model by assessing, on a quantitative footing, the current State and the future Risk of Urban vulnerability on the basis of both the available socio-economic indicators and expert preferences. To obtain the optimal satisfaction of the attributes demanded by both USP and UV research, this method was designed, by means of its optimization module, to maximize the subjective preferences expressed by practitioners (DO-1, Figure 2), maximize the robustness of UVA models (DO-2, Figure 2), maximize their overall goodness-of-fit (DO-3, Figure 2), maximize the similarity among indicators of different political-administrative scales and the dynamic connection over time (CO-1, Figure 2), and maximize the goodness of fit at each scale (CO-2, Figure 2). Moreover, while other assessment models fail to take into account, when assessing vulnerability, of the linkage between political-administrative scales, the method designed relates them in the quantitative assessment framework, thus incorporating the context-dependent character of urban vulnerability. On the other hand, its control module allows interaction (I-1 to I3) between practitioners, decision-makers (DMs), and the model while providing tradeoffs between objectives. From these trade-offs, guidelines can be elicited which, together with the participation of the DMs in the process, furnish these latter with an improved knowledge of the problem at issue (Torres-Machi et al., 2017), enabling them to carry out an informed selection.

Therefore, the novelty of the method presented mainly relies on the following aspects: first it enables DMs, through a process embodying the abovementioned attributes, to make an informed selection of a UVA model; second, it provides a quantitative assessment of both the state and risk of UV; and finally, it takes into account, within the qualitative assessment framework, the multiple scales shaping the political-administrative context of the entities within the area evaluated.

The remainder of this paper is organized as follows. In the methods section, the general workflow describing the relation between the control and optimization modules and the quantitative framework, as well as a detailed description of these three modules, is presented. The methodology proposed is applied to an actual case in the case study section, and the results are presented and discussed in the subsequent section. Finally, general conclusions are drawn in the last section. 


\section{Methods.}

This section describes the whole process, analysing its elements one by one as indicated in Figure 1. We begin describing how the process works in general and then, for each of its stages, detailed explanations are given.

\section{General Workflow:}

For UVAs, satisfying the above mentioned requirements means integrating them into a framework. For this purpose, a general workflow comprising three modules, namely the Assessment, Optimization and Control modules (Figure 1), was designed. The Assessment Module, which is the UVA model itself, undertakes accounting for subjectivity and for the dynamic character of urban vulnerability. The second module, namely the optimization model, contributes toward handling the many-objective, multiscale, cognitive and robustness requirements by encoding them into the optimization objectives. In addition, both its subjectivity and its dynamic nature should be considered, which has been addressed by embodying these features in the former modules and by running the general workflow through a discursive approach (Dominguez et al., 2011). The latter took form as the Control Module implementing an iterative dialogue between the DMs and the model.

The idea is to elicit general guidelines by following a three-step process. In the first step, the quantitative and qualitative information required by the UVA Assessment Module (Figure 1, 2.1) is obtained. Then, the Assessment Module is executed and, in a second step, a set of Pareto-optimal models (Figure 1, S-1 \& S-2) is elicited through the Optimization Module (Figure 1, 2.2). As the third step, the Control Module allows for the inference of the guidelines for the selection of a characterization model (Figure 1, G). Steps 2 and 3 are repeated for every subsequent period.

\subsection{Control module (Figure 1, 2.3)}

The control module implements the discursive approach, and operates upon the Optimization and the Assessment modules by implementing three main interactions (Figure 1): I-1, introducing a set of basic conditions, the entities to be classified as vulnerable or non-vulnerable, into the assessment model; I-2, choosing an initial model, via the designed characterization framework, capable of achieving the desired behaviour in terms of robustness, subjective preferences and GOF; and I-3 giving continuity to the starting model by selecting that of the subsequent period. For each entity, year and period, the UV State and Risk were assessed, allowing its integration in strategic planning 
processes.

The interaction I-1 implies that the whole model will be built under some basic, subjective assumptions relating both to criteria used for the basic evaluation and its thresholds. In addition, since the second and third interactions require the selection of one model from many models via DMs, subjectivity is also present in those stages. Nevertheless, though improvement in objectivity should be pursued to satisfy the already noted UVA requirements (Munda, 2004), a certain degree of subjectivity is unavoidable, and therefore acceptable in the field of vulnerability assessment methods (Solín, 2012).

\subsection{Optimization module (Figure 2, 2.2)}

The problem of the modelling system's behaviour was addressed via the multiple objectives the optimization model sought to achieve (Boada et al., 2016). Therefore, with the aim of fulfilling the already-stated requirements for UVA methods, the behaviour was evaluated in terms of the preferences of practitioners as the required aggregation of external judgment (Adger, 2006), robustness (Hermeling et al., 2013), and GOF (Boada et al., 2016), each of these being an objective in the optimization process (Figure 2, DO 1 to 3 ; Table 2 , f obj 1 to 3 ).

This resulted in the formulation of a many-objective optimization problem (MOOP) aiming to find the best compromise solutions for the designed characterization framework. For this purpose, the aforementioned qualities of robustness, GOF and preferences of DMs were introduced as decision objectives in the MOOP (Figure 2, DO). The objectives should not only demonstrate the model's behaviour but also provide them with the required supervision. This supervision must ensure proper guidance of the process of searching for solutions and eventually achieve the compliance with the minimum conditions where required. This can be settled by aggregating the control objectives into the MOOP itself and by introducing constraints in the form of penalty functions (Zhou et al., 2011). Control objectives (Figure 2, CO) handling issues regarding both the multi-scale and the dynamic nature of urban vulnerability were therefore incorporated in the MOOP. In addition, penalty functions were introduced in the UVA. These constraints make eventual violations of the conditions evident to the statistical techniques employed across the whole process by penalizing the value of the solution in the objectives, allowing the DM to decide whether to discard them.

In this way, embodying the already stated requirements into the process entailed the development of the following objectives: 


\section{Definition of decision objectives (DO):}

Decision objectives describe the behaviour of a set of solutions (Fig. 2) and offer criteria for selecting one of them:

Subjective preferences (DO1). This objective was evaluated as the sum, over the set of indicators shaping the model, of the weights derived for each variable/indicator:

$$
P=\sum_{k=1}^{n} w_{k}
$$

In order to evaluate the degree to which indicators of any UVA model are preferred by practitioners, the preferences of these latter should be previously modelled. Analytic Hierarchy Process (AHP) is a systematic method comprising participatory processes (Pellicer et al., 2016) that, with the aim of grasping the stakeholders preferences, has been commonly used in the field of strategic planning (Kubler et al., 2016; Penades-Pla, et al., 2016) for the aggregation of qualitative information concerning social sustainability (Zamarrón-Mieza et al., 2017). Specifically, AHP has proved to be effective for urban management when planning the participation of citizens by recognizing their values (Hong \& Chung, 2016), as well as for grasping preferences for indicators (Khalil et al., 2016) (our case). Furthermore, AHP can be integrated within many-objective optimization processes (Leong et al., 2017; Yepes et al., 2015). Therefore, we adopted this method for modelling the preferences of practitioners (DMs) for indicators, and integrating them within the MOOP process.

For this purpose, a questionnaire was developed in which the indicators were structured into a hierarchy of 3 levels: goals, vulnerability approaches, vulnerability aspects and vulnerability indicators (Table 1). This hierarchy basically followed the well-established qualitative analysis of the selected indicators made by Alguacil et al. (2014). For the administration of the survey, a letter of invitation and the questionnaire were distributed to experts (Khalil et al., 2016). The respondents were asked to assess, via pair-wise comparison of elements within the same hierarchical level, how much each element was preferred over the others, as a useful indicator for evaluating urban vulnerability in an area. Therefore, biophysical aspects were pair-wise compared with the socio-economic aspects, which in turn were internally compared, and so on. This enabled identifying the relative importance, in terms of weights of variables, given by the involved practitioners (DMs) to all the assessed concepts.

Robustness (DO2). Uncertainty analysis conducted via the Monte Carlo simulation method is recognized as an appropriate method for assessing the robustness of index- 
based rankings (Marozzi, 2016; Hermeling et al., 2013), which is the case here. Broadly speaking, this method analyses how a model's outcome behaves when the inputs vary within an expected range of values. Having performed the Monte Carlo simulation, the robustness of the model can be evaluated by assessing, for each $k$ input variable, the relative size of its variance $v$ with respect to its mean $m$, and then aggregating these ratios, obtained for the $n$ variables composing the model, to assess its overall robustness $R$ :

$$
R=1 /\left(\sum_{k=1}^{n}\left(\frac{v_{k}}{m_{k}}\right)\right)
$$

Models with small variance in comparison with the mean are robust (Hermeling et al., 2013). This method adds sensitivity to the uncertainty analysis, thereby enhancing the information thus obtained. Therefore, we selected this approach for our method. This objective was stated as

Goodness of fit (DO3). The goodness of fit (GOF) is crucial when treating both the accuracy and validity of a model. This has been commonly tackled by analysing the model's output error in general (Boada et al., 2016). The use of the Normalized Root Mean Square Error (NRMSE) as a criterion to select the most appropriate model in the case of the existence of extreme values in the data-set has been successful in the development of UVA methods (Karagiorgos et al., 2016; Akumaga et al., 2017). We therefore formulated the GOF objective, for each $s c l$ scale, as follows:

$$
G O F_{s c l}=\sqrt{\frac{\sum_{i=1}^{p}\left(S_{i}-O_{i}\right)^{2}}{p} \times 100 / \bar{O}}
$$

Where the index $i$ runs over $p$ number of observations, and $S_{i}, O_{i}$ and $\bar{O}$ respectively represent the value predicted by the model, the value observed and mean of the values observed.

In consequence, the overall GOF is formulated as the sum of all the GOF by scales:

$$
G O F=\sum_{s c l=1}^{n s c a l e s} G O F_{s c l}
$$

Where nscales is the number of political-administrative scales considered.

\section{Definition of control objectives (CO):}

Control objectives are the objectives that contribute to guiding the search process and identifying the solutions with the above mentioned attributes that are demanded for UVA, despite their not being relevant in the selection of the characterization model. 
Both resilience and vulnerability are complex, context-dependent concepts that dynamically change over time and space. The latter refers not only to the physical position of the analysed systems but also to the socio-political scale by which it is affected (Fuchs \& Glade, 2016; Herslund et al., 2016). The proposed UVA framework addresses this feature by comparing the evolution of systems along time and political-administrative scales. Therefore, some control is required in linking the different moments and scales considered in the analysis. For this purpose, two classes of control objectives additional to the basic classes were employed.

The first class provided a criterion through which the different intervals constituting the overall time span are connected, and was evaluated in terms of the higher $p$-value resulting from the ANOVA test (Mzolo et al., 2015):

$$
H_{0, k}=\mu\left(t_{k-1}\right)=\mu\left(t_{k}\right)
$$

Where $k$ and $t$ are, respectively, the interval analyzed and the instant of time that is both the end point of the $k$ period and the prediction projected, for that instant, by the risk assessment produced at the $k-1$ period. That relation enabled us to connect the time slices by looking for models that behave alike, which we implemented through the maximization of those $p$-values as the first of the control objectives (Figure 2, CO1).

The second class, on the other hand, gathers a series of objectives, which afforded models with the best fitting for each scale, and therefore made more explicit the effects that between them might be conveyed to hierarchically-dependent systems. This was implemented by setting up as many objectives as scales, maximizing the GOF corresponding to each scale (Figure 2, CO2). For the sake of simplicity, we looked after some heterogeneity in the variables selected across the scales by introducing a criterion of similarity among them. This was evaluated through the Euclidean model, whose distances were transformed into similarity as the inverse of the modified exponential decay (Jo et al., 1997):

$$
S_{a b}=e^{-d_{a b}}, \forall d_{a b}
$$

Where $S_{s b}$ is the similarity between cases $a$ and $b$, and $d_{a b}$ is the Euclidean distance between these cases.

The increase in the number of objectives arising from having to consider those dynamic aspects impelled us to a many-objective configuration of the problem, which is considered an appropriate method for dealing with real-world, complex problems (Zhou et al., 2011). Table 2 portrays all the objectives considered in the many-objective configuration (column B), which can be formulated as: 


$$
\text { minimize } F(x)=\left(f_{1}(x), \ldots, f_{o b j}(x)\right) T
$$

s.t.x $\in \Omega$,

where $\Omega$ is the decision space, $x \in \Omega$ is a decision vector and $o b j$ is the objective function accordingly to Table 2 .

\subsection{UVA Assessment Module (Figure 2, 2.1)}

\section{Data Pre-processing}

As mentioned in the general workflow section, the process begins with the interaction 1 (Figure 1, I-1), in which basic indicators and thresholds are decided. This interaction allows performing a basic identification of entities as vulnerable and non-vulnerable in a given time, depending on whether thresholds are exceeded or not (Figure 2, BC-1). This classification was carried out for the first and last years of each period considered, allowing the statement of a basic UV evolution classification (Figure 2, BC-2) into three categories, according to whether entities changed from non-vulnerable to vulnerable, or vice-versa, or experienced no change. The result of this classification (Figure 2, BE-n) was aggregated as a dynamic variable always present in the analysed data set, and used as a reference to supervise the searching of the proper set of indicators in the Optimization Module (Figure 2, DO3).

\section{Ranking of UV State (Figure 2, O-1):}

PCA is a statistical technique based on the analysis of variance that has previously been used to both assess the relative importance of socio-economic and physical indicators (Shen et al., 2012) and to build resilience rankings (Kotzee \& Reyers, 2016). Further, PCA relies on variation and covariation of the data and produces factors accounting for the variance of the data set. A set of factors explaining at least $85 \%$ of the variance of data is regarded an adequate model. On this basis, a comprehensive assessment model can be developed by going through the following four step process (Shen et al., 2012):

i. Selection of a set of factors accounting for more than $85 \%$ of total variance.

ii. Transformation of principal components into a relation between a correlation coefficient in the factor loading matrix $\left(r_{x_{i} P C_{j}}\right)$ and the coefficient vector of each principal component (denoted by $a_{i j}$ ). That relation is given by Equation (8), with $\lambda_{p c}$ being the eigenvalue of the $p c^{\text {th }}$ principal component factor.

$$
r_{x_{i} P C_{j}}=\sqrt{\lambda_{n p c} a_{i j}}
$$

iii. Using this method, as many equations as principal components are obtained, allowing us to calculate a general equation using which the weight of each variable can 
be derived. This can be obtained by normalizing each eigenvalue to the sum of eigenvalues of the whole set of components (Lin \& Zhang, 2005; Zhang, 2006), as shown:

$$
S V=\sum\left(\frac{\lambda \mathrm{npc}}{\lambda 1+\lambda 2+\cdots+\lambda \mathrm{tpc}}\right) P C n p c
$$

iv. The last equation provides normalized values of each $\lambda \mathrm{i}$ for each principal component $P C_{i}$, that is to say, for each one of the equations obtained in in step (ii), and therefore allows directly relating the data variables through their weights calculated in step (iii), with the comprehensive assessment model outcome, $S V$. We can now pass each observation though the assessment model to obtain a corresponding Vulnerability State value, which will be the criterion used for its ranking (Figure 2, O-1).

\section{Risk and opportunity (Figure 2, O-2):}

For each entity, the risk of becoming more vulnerable, i.e. of losing positions in the vulnerability state ranking, was obtained as a result of the product of the probability of becoming more vulnerable and the impact on the ranking previously derived (Villa et al., 2016; Dai et al., 2002; Kaplan\& Garrick, 1981; Brooks, 2003).

- Risk Evaluation: Impact Component (Figure 2, R-1). For each scale, entities were ranked accordingly to their UV state. The assessment of the impact for each period relates its evolution, in terms of positions gained or lost in this ranking, with that of the indicators shaping the model. Using variance as a measure of impact has been previously attempted in the field of risk assessment (Osanloo \& Rahmanpour, 2017; Parvizimosaed et al., 2017; Mi et al., 2017).

For the formulation of impact, multiple linear regression was performed using the data set variation from the starting to the finishing year of the period considered as predictors and the UV state rank variation, i.e. number of positions gained or lost, as the response. A minimum value of 0.3 for $R^{2}$ parameter and a maximum value of 0.05 for the $p$-value were granted by setting these conditions as constraints via a penalty function (Zhou et al., 2011), affecting the GOF objective in the optimization process. The coefficients thus obtained were used to assess the impact for each entity.

- Risk Evaluation: Probability Component (Figure 2, R-2). Discriminant analysis has been widely used as a density estimation approach to tackle the probability estimation problem (Malley et al., 2012; Nielsen et al., 2016) and is therefore used for risk assessment purposes. This supervised technique aims to find the so-called 
discriminant functions, following the principle of maximizing the difference between two classes while minimizing that among members of the same group. In addition, for each observation (entity), the posterior probability of belonging to each class is given.

The model uses DA to assess the possibility of falling within each one of the three possible classes for all observations. These classes refer to the type of evolution experienced by each observation through the period of time considered: negative, stable or positive, when observations exhibited a vulnerable, indifferent or resilient behaviour, respectively, in terms of the basic classifications elicited in the data pre-processing stage (Figure 2, BE-1 to 2). As a result, DA was performed by considering the evolution of variables as predictors and that of the basic classification as responses, thus obtaining the probabilities required for the risk assessment.

\section{Case study}

\subsection{Assessment of Urban Vulnerability in Spain}

We considered the presented UVA method's application for assessing the UV in Spain. Following the three-step process mentioned above, the objective is to provide DMs with the guidelines required for the selection of a proper UVA model. Spain is a country concerned with UV to the point of having invested, from 1999 to 2013, up to 1.103.107.807 $€$ through the URBAN I, URBAN II, and Iniciativas Urbanas-FEDER European programs, which were designed to face urban vulnerability. Based on the work of Gómez et al. (2014), this country has developed an Observatory of Urban Vulnerability (OUV) that plays a key role in the development of strategies involving housing, transportation and infrastructure investments (Infrastructure, transportation and housing plan-PITV 2012-2020, Spanish Ministry of Public Works). Using the data obtained from the population and housing censuses of 1991, 2001 and 2011 of the Spanish National Institute of Statistics (INE), this observatory provides an assessment of vulnerability levels on a neighbourhood scale for cities of the country with more than 100,000 inhabitants or the capital of the province (OUV). Also, they have put the data for 1991 and 2001 that were used for the assessment at the disposition of the public. As the first step of our process, we retrieved the data of those years. In order to extend the assessment, we added the data corresponding to the scales of city, province and autonomous community (INE), and also added more variables, regarding the built environment, that were available (Table 1). In synthesis, for the years 1991, 2001 and 2011, data corresponding to 36 indicators for up to 142 cities, 52 provinces and 19 regions (17 autonomous communities plus Ceuta and Melilla) were collected. For the suburbs, of the 
687 neighbourhoods identified, only material corresponding to the years 1991 and 2001 was used, since that of 2011 was unavailable.

\subsection{Collection and pre-treatment of data and expert-judgment}

All this information was assembled in an SQL database, which in turn was linked to the Matlab® code automating the whole process described in the methodology section, including the UV assessment framework (2.4), the optimization (2.3) and control (2.2) modules. Since the statistical techniques used in the UVA required a normal distribution in the input, a Box-Cox transformation was applied (Box \& Cox, 1964). At the same time, based on the AHP method described above, a survey was conducted of experts in urban planning, resulting in 10 answers in which consistency was tested (Saaty, 1990). According to Saaty and Özdemir (2014), AHP does not require a pre-determined number of surveys for granting its validity. During the data entry, the consistency of the responses was evaluated and improved if possible without altering priorities in judgments (Singh \& Nachtnebel, 2016). Of the 10 responses, only 9 were accepted for further analysis. Then, the overall preference of each UVA practitioner was elicited as the non-normalized geometric mean of all individual preferences, and the results are shown in Table 1.

\subsection{Set-up of the process}

As with the basic classification of vulnerability, we accepted the standard adopted by OUV of setting up a threshold for a set of basic indicators. Those basic indicators were the proportion of unemployed population, proportion of population without studies, and the proportion of dwellings, or of people living in dwellings without bathroom or toilet (OUV). As a result, the model regarded as vulnerable those entities falling 1.5 times further than a given reference. As this reference, the OUV considered values at the country scale and compared with it all neighbourhoods in the country regardless of the city, province and region containing, and therefore contextualizing, them. Since UV is context dependent (Fuchs \& Glade, 2016; Herslund et al., 2016), instead of the absolute approach employed by the OUV we applied a relative one in which entities were referred to that entity of the upper scale containing them.

As the second step, we conducted the dynamic process associated with the control and optimization modules described in the methodology section. Based on the methodology reported, the model was formulated as a nine-objective optimization problem (Table 2) with binary variables, i.e. the values the variables can take are 1 or 0 depending on whether they exist or not in each characterization model. For the robustness objective, we followed the process described in the methodology section, producing 100 random outcomes for each candidate via the Monte Carlo simulation method. Since we had 
several scales, the decision objectives were expressed as the sum of the results corresponding to each scale, except for the case of subjective preference, expressed as the mean of the values. The program was coded in Matlab ${ }^{\circledR}$ with an INTEL ${ }^{\circledR}$ CoreTM i7$4712 \mathrm{CPU}$ processor at $2.3 \mathrm{GHz}$. Starting from an initial random population of 300 individuals, 500 iterations (a number of iterations that has been found acceptable for the case of multi-objective optimization of binary-real coded variables (Abdul-Rahman et al., 2013) were set as the maximum number of generations to be obtained (Alajmi \& Wright, 2014). Crossover and mutation probabilities were set to 0.6 and 0.5 , respectively.

\subsection{Run of the process}

We thus obtained a set of Pareto-optimal UVA models corresponding to the first period, i.e. 1991-2001, which we analysed in order to obtain the guidelines of their behaviour. As expected, these solutions show a trade-off between the criteria used for its assessment. With this knowledge, a model was selected and the UVA framework was applied for period 2 (2001-2011). Again, a set of optimal UVA models was obtained. This time, however, during the optimization process a dynamic control for time was added to the set of previous objectives, which served as criteria for the evaluation of alternatives (Table 2). This additional objective enabled DMs to select among those UVA models of the second period better connected with that of the first period providing the feedback. As a result of that latter, a desired behaviour was identified and the corresponding selected UVA model was realized, which enabled ranking the neighbourhoods, cities, provinces and regions assessed from less to more vulnerable.

To test the performance of the breaking down of the overall GOF objective into as many factors as there are scales, a comparison was made between the results obtained in both cases, and the results are presented and discussed at the end of the next section.

\section{Results and Discussion}

\subsection{Guidelines for Period 1, 1991-2001}

The above mentioned process was used to yield results for periods 1 and 2 .

In the first period, i.e. 1991-2001, a set of Pareto-optimal solutions, represented in Figure 3 , was obtained. To improve the extraction of knowledge from the results, we furthered the analysis by using a cognitive approach entailing a comparison of the best solutions for each decision objective (Table 1).

The interpretation of these results provides guidelines regarding the trade-offs between the decision objectives just mentioned. This enables us to draw conclusions on the 
behaviour of models in terms of their robustness, coincidence with expert's preferences, and their GOF. In addition, with the knowledge thus acquired, DMs are in a better position to define the desired behaviour to subsequently select, directly from the Pareto front, a UVA model that gives way to the evaluation of period 2.

Figure 4 portrays the trade-off between the robustness and GOF objectives. Solutions performing well in terms of robustness are poor in terms of GOF and vice versa, showing that these two objectives are contradictory. In addition, we implemented a semiautomated alternative for enhancing the extraction of guidelines (Boada et al., 2016). The solutions gathered were clustered according to their performance and the similarityamong-scales control objective. Solutions with low similarity, marked with asterisk, are spread throughout the space, while those with higher similarity, marked with squares, were concentrated close to the best solution for the GOF criterion. The solutions with higher similarity, in turn, are also directly related with those performing better for the preferences objective (Figure 5) and inversely related with the robustness criterion (Figure 5). As a result, for the first period the following guidelines were elicited (Figure $2, \mathrm{I}-1)$ :

- Models with more robust behaviour are less related to practitioner's preferences and have less accuracy. In addition, in such models, the similarity between the set of indicators across political-administrative scales is low.

- $\quad$ Preferences of practitioners, GOF and similarity between scales are aligned with each other.

\subsection{Guidelines for Period 2, 2001-2011}

With the knowledge thus obtained, we decided to choose, as the reference for the time dynamic-control objective of the second period, the most robust model among the models fitting the guideline above.

The results for the second step are presented in Figure 6. The analysis of these results allows extracting, as in the previous case, the guidelines for identifying a desired behaviour. For period 2, solutions were clustered according to the time-dynamics control objective instead of the similarity across scales. The time-dynamics criterion's performance is slightly and directly related with that of GOF and strongly and inversely related with those of robustness and preferences which, in turn, also exhibit an inverse relation among themselves.

Regarding the GOF objective, Figure 6 shows that the solutions most preferred by practitioners have not overcome the 0 value in the GOF scale, which means that the threshold, required for $p$-value and $R^{2}$ values of the impact assessment, was not reached 
in any of the scales, penalizing the GOF. Besides, the inverse relation which for the case of GOF and robustness was noticeable in period 1 is also present in period 2. Models preforming better in terms of the time-dynamics objective are present throughout the space of compromise solutions. However, they are clearly concentrated in the proximity of solutions better for the GOF but worse for the preference objectives (Figure 6).

On this basis, the following guidelines can be drawn for period 2 (Figure 2, I-2):

- The most preferred solutions are not the best dynamically connected over time and do not fulfil the statistical conditions required by the UVA framework. The DM should decide whether they wish to relax those requirements.

- The inverse relations identified in period 1 between the preferences and GOF objectives and the robustness objective are still present in period 2. This, together with the fact that the time-dynamics criterion is akin to that of the GOF, affords a range of solutions behaving well in terms of the GOF and time-dynamics, yet medium to poor for preferences and robustness criteria, respectively.

\subsection{Improvements rendered by the many-objective approach}

Table 1 portrays how the set of variables selected as indicators changes across scales for better representing the UV. The use of a many-objective approach has proven efficient for the sake of attaining the best overall GOF by pursuing the best GOF scores by each scale, allowing UVA to consider the complex character of this concept. Table 1 also depicts the equality in the share of importance bestowed upon biophysical and socioeconomic aspects, suggesting the preference of practitioners for comprehensive approaches considering both standpoints. This is consistent with the conclusions of previous publications in the literature, considering the comprehensive approach as a requirement for attaining more-evolved UVAs.

Regarding the employment of the many-objectives approach for dealing with the multiscale character exposited in the control objectives section, Table 2 portrays a comparison between the results obtained by using this approach with those from a single overall GOF objective. The results show that for all periods, the addition of GOF objectives by scale contributes to improve the results in the overall GOF. This leads, however, to slightly worse results for the preferences and multi-scale objectives in the case of period 1, and for that of robustness in period 2.

As to the optimization algorithm employed, NSGA-II modified the selection operators of the original NSGA. Via this approach, the lack-of-elitism problem was alleviated but not 
completely overcome. In fact, the state-of-the-art of evolutive optimization algorithms suggests that the most widely used selection operators still do not work well when dealing with more than three objectives, i.e. with many-objective problems (Zhou et al., 2011), an idea which the present paper seems to support. Our results demonstrate the difficulties this algorithm has to avoid the loss of performance in some objectives, when their number of these objectives increases.

\subsection{Improvements regarding the current UVA in Spain}

On the other hand, the share of importance conferred by practitioners on the indicators available to assess urban vulnerability greatly varies from one indicator to another. Table 1 shows how this relative importance varies from the most to the least preferred indicators, pointing out Population density, Dwellings density and Elder 75 years or more, as the most important for the experts consulted. In contrast with the assessment adopted by the Spanish Government, the method hence proposed embodies this information and allows selecting UVA models shaped by those indicators considered more relevant by practitioners for the assessment of both the Vulnerability State and Risk. As well, a comprehensive assessment of the whole country, across its different politicaladministrative scales, of entities contextualized within their environment, is provided. With this information, DMs can identify both current states of vulnerability and trends for the future, and extend the evaluation of entities beyond the current mere classification into vulnerable or non-vulnerable. Further, it allows a deeper and wider analysis of the UV problem, and the design of more complete and better adapted strategies. For example, entities still at the first stages of degradation but yet at high risk, which would be considered as a prior target, can now be identified, and plans can accordingly be made.

Through the employed cognitive approach, DMs are now enabled to select, according to the knowledge acquired, a proper solution from among the set of compromise solutions yielded by the optimization module (Figure 2, 2.2). This mechanism serves, in fact, as the scenario generator required for developing bottom-up uncertainty analysis methods (Hall et al., 2012). For period 2, 80 compromise solutions fulfilling the statistical requirements were found, with values ranging from 2,002.35 to 8,217.39 in the case of the Robustness objective, from 1.09 to 1.85 in the case of GOF, and from 0.46 to 0.86 in that of Preferences.

\section{Conclusions and further research}

In pursuit of sustainable urban development, the improvement of UVA methods is a key 
issue that has attracted the attention of many governments (Fekete, 2009; Rigillo \& Cervelli, 2014; Malekpour et al., 2015). This improvement can be realized by developing models integrating the features demanded in this field. This paper puts forward a method integrating the aforementioned requirements that can be used to determine the optimum set of indicators which, for the proposed UVA assessment model, follow a desired behaviour. This behaviour is modelled in terms of robustness, GOF and preferences of practitioners, and the overall process is formulated as an MOOP. Moreover, a set of underlying control objectives provided insights on the dynamic character of UV over time and context.

The proposed method uses a discursive approach in which DMs and the model interact and give each other the required support, which affords DMs with more knowledge on the dynamic interactions between criteria. This enables them to make an informed, evidence-based decision on the issue at stake. First, this study introduced the aspects required for UVA and proposed the formulation of a process encompassing all requirements, as an MOOP to be solved by the NSGA-II algorithm. Then, the whole process was described and tested via a case study. For this purpose, Spain has been used as an example, and quantitative data on the neighbourhood, city, province, region and country political-administrative scales was gathered. In addition, qualitative information in terms of the preferences of practitioners for the indicators available was elicited, showing great differences from one practitioner to another. With this information, the process was performed, and the results showed that the method is endowed with the qualities demanded and is able to draw out general guidelines of the model's behaviour. Finally, the guidelines suggest that for the proposed UVA assessment model it is possible to select models better dynamically connected over time and fitting well in terms of GOF, at the expense of a medium or bad performance in preferences and robustness.

As to the Urban Vulnerability Assessment module, the method proposed provides UVAs which involve practitioners by taking into account their subjective preferences, are robust in the face of data uncertainty, and are statistically derived through commonly accepted techniques. Since there are UVA methods making use of these features separately, the novelty of this work consists in their integration to take advantage of the benefits of their synergies. Besides, the process provides a UV State and Risk Assessment according to the requirements demanded, enabling planners to carry out an improved analysis of the UV problem in Spain in order to develop better adapted strategies.

All this together means moving on the assessment of Urban Vulnerability in Spain, from the earlier stages of development in urban strategic planning and vulnerability 
assessment, to the discursive and adaptive governance stages characterizing present trends in these fields (Malepour et al., 2015; Fussell et al., 2006). At the same time, the method proposed helps bridge the gap as to the development of the demanded improvements in adaptive governance and strategic planning in the context of climate change and socio-economic transformation.

As to modelling of the multi-scale nature of urban vulnerability, our study shows how to use many-objectives approaches to tackle this problem, improving the outcome of the optimization in the objective affected.

Despite the remarkable outcomes, there are still limitations to this study. More research is required on the selection of the basic criteria upon which the whole process rests, exploring different indicators, thresholds and references. Also, the use of other machinelearning methods such as neural networks, SVM or Naïve Bayes networks, can be tested to obtain more accurate models. In addition, this methodology embodies a basic dynamic control over time and context that should be improved in future research focusing on this issue. Regarding this latter, research on the spatial correlation among entities could disclose valuable information with which to improve the assessment module. Finally, in addition to the abovementioned limitations, two more can be pointed out for the case study. First, the number of expert-judgment collected for the elicitation of preferences was relatively low, suggesting a broader survey in order to obtain more representative values. Second, the output of the process was a rather large set of optimum solutions, among which DMs must choose one with the aid of the guidelines provided. The implementation of dimension-reduction techniques, such as cluster analysis, would facilitate the decision making by synthesizing the set of optimum solutions into a smaller, affordable number of representative ones.

\section{List of Abbreviations:}

UVA: Urban Vulnerability Assessment

UV: Urban Vulnerability

USP: Urban Strategic Planning

DM: Decision Maker

GOF: Goodnes Of Fit

RMSE: Rooth Mean Square Error 
NRMSE: Normalized Rooth Mean Square Error

AHP: Analytic Hierarchy Process

MOOP: Multi Objective Optimization Problem

DA: Discriminant Analysis

PCA: Principal Componentes Analysis

NSGA-II: Non-dominated Sorting Genetic Algorithm

SVM: Support Vector Machine

\section{List of Notations:}

$P$

$w_{k}$

$n$

$R$

$v$

$m$

$\mathrm{GOF}_{\text {scl }}=$

$i$

$p$

$S$

$O$

$\bar{O}$

nscales

$H_{0, k}$

$\mu$

$S_{a b}$

$e$

$d_{a b}$

F

$o b j$

$x$

$\Omega$

$T$

$r_{x_{i} P C_{j}}$

tpc

$n p c$

$P C$

$a_{i j}$

$\lambda$

SV
Preferences

Weight of the $\mathrm{k}$ indicator

Total number of indicators

Robustness

Variance of the set of monte carlo simulations

Mean of the set of monte carlo simulations

Goodness of Fit for the scale number scl

Number of each observation

Total number of observations

Value predicted

Value observed

Mean of the values observed

Total number of scales

Null hypothesis for the ANOVA test of equal means for the k period

Means at the $t$ instant

Similarity between $\mathrm{a}$ and $\mathrm{b}$

Number e

Euclidean distance between $\mathrm{a}$ and $\mathrm{b}$

Function of the $f$ continuous objective functions

Total number of objective functions

Decision vector

Decision space

Set of Pareto-optimal solutions

Factor loading matrix

Total number of principal components

Number of the principal component

Principal component vector

Coefficient vector of each principal component

Eigenvalue of each principal component

State of Vulnerability 


\section{References}

Abdul-Rahman, O. A., Munetomo, M., \& Akama, K. (2013). An adaptive parameter binary-real coded genetic algorithm for constraint optimization problems: Performance analysis and estimation of optimal control parameters. Information Sciences, 233, 54-86. article.

http://doi.org/http://dx.doi.org/10.1016/j.ins.2013.01.005

Adger, W. N. (2006). Vulnerability. Resilience, Vulnerability, and Adaptation: A CrossCutting Theme of the International Human Dimensions Programme on Global Environmental Change Resilience, Vulnerability, and Adaptation: A Cross-Cutting Theme of the International Human Dimensions Programme, 16(3), 268-281. http://doi.org/http://dx.doi.org/10.1016/j.gloenvcha.2006.02.006

Akumaga, U., Tarhule, A., \& Yusuf, A. A. (2017). Validation and testing of the FAO AquaCrop model under different levels of nitrogen fertilizer on rainfed maize in Nigeria, West Africa. Agricultural and Forest Meteorology, 232. http://doi.org/10.1016/j.agrformet.2016.08.011

Alajmi, A., \& Wright, J. (2014). Selecting the most efficient genetic algorithm sets in solving unconstrained building optimization problem. International Journal of Sustainable Built Environment, 3(1), 18-26. article. http://doi.org/http://dx.doi.org/10.1016/j.ijsbe.2014.07.003

Alguacil Gómez, J., Camacho Gutiérrez, J., \& Hernández Aja, A. (2014). La vulnerabilidad urbana en España. Identificatión y evolutión de los barrios vulnerables. Empiria, (27), 73-94.

Birkmann, J., Garschagen, M., \& Setiadi, N. (2014). New challenges for adaptive urban governance in highly dynamic environments: Revisiting planning systems and tools for adaptive and strategic planning. Urban Climate, 7, 115-133.

Brooks, N. (2003). Vulnerability, Risk and Adaptation: A Conceptual Framework. Tyndall Centre for Climate Change Research, Norwich, UK.

Boada, Y., Reynoso-Meza, G., Picó, J., \& Vignoni, A. (2016). Multi-objective optimization framework to obtain model-based guidelines for tuning biological synthetic devices: An adaptive network case. BMC Systems Biology, 10(1). http://doi.org/10.1186/s12918-016-0269-0 
Box, G. E. P., \& Cox, D. R. (1964). An analysis of transformations. Journal Of The Royal Statistical Society Series B-Statistical Methodology, 26(2), 211-252. article.

Chang, L.-F., \& Huang, S.-L. (2015). Assessing urban flooding vulnerability with an energy approach. Landscape and Urban Planning, 143, 11-24. http://doi.org/http://dx.doi.org/10.1016/j.landurbplan.2015.06.004

Dai, F. C., Lee, C. F., \& Ngai, Y. Y. (2002). Landslide risk assessment and management: an overview. Engineering Geology, 64(1), 65-87. article. http://doi.org/http://dx.doi.org/10.1016/S0013-7952(01)00093-X

Dominguez, D., Truffer, B., \& Gujer, W. (2011). Tackling uncertainties in infrastructure sectors through strategic planning: the contribution of discursive approaches in the urban water sector. Water Policy, 13(3), 299-316.

Fekete, A. (2009). Validation of a social vulnerability index in context to river-floods in Germany. Natural Hazards and Earth System Sciences, 9(2), 393-403. JOUR.

Fuchs, S., \& Glade, T. (2016). Foreword: Vulnerability assessment in natural hazard risk-a dynamic perspective. Natural Hazards, 82. article. http://doi.org/10.1007/s11069-016-2289-x

Füssel, H.-M., \& Klein, R. J. T. (2006). Climate Change Vulnerability Assessments: An Evolution of Conceptual Thinking. Climatic Change, 75(3), 301-329. http://doi.org/10.1007/s10584-006-0329-3

Füssel, H.-M. (2007). Vulnerability: A generally applicable conceptual framework for climate change research. Global Environmental Change, 17(2), 155-167. http://doi.org/10.1016/j.gloenvcha.2006.05.002 
Giezen, M., Salet, W., \& Bertolini, L. (2015). Adding value to the decision-making process of mega projects: Fostering strategic ambiguity, redundancy, and resilience. Transport Policy, 44, 169-178.

Hall, J. W., Lempert, R. J., Keller, K., Hackbarth, A., Mijere, C., \& Mcinerney, D. J. (2012). Robust Climate Policies Under Uncertainty: A Comparison of Robust Decision Making and Info-Gap Methods. Risk Analysis, 32(10), 1657-1672. article. http://doi.org/10.1111/j.1539-6924.2012.01802.x

Hermeling, C., Löschel, A., \& Mennel, T. (2013). A new robustness analysis for climate policy evaluations: A CGE application for the EU 2020 targets. Energy Policy, 55, 27-35. http://doi.org/10.1016/j.enpol.2012.08.007

Herslund, L. B., Jalayer, F., Jean-Baptiste, N., Jorgensen, G., Kabisch, S., Kombe, W., ... Vedeld, T. (2016). A multi-dimensional assessment of urban vulnerability to climate change in Sub-Saharan Africa. NATURAL HAZARDS, 82(2), S149-S172. article. http://doi.org/10.1007/s11069-015-1856-X

Hong, C.-Y., \& Chung, E.-S. (2016). Temporal variations of citizens' demands on flood damage mitigation, streamflow quantity and quality in the Korean Urban watershed. Sustainability (Switzerland), 8(4). JOUR. http://doi.org/10.3390/su8040370

INE. Census 1991. Retrieved 03/28/2016 from:

http://www.ine.es/censo91/en/seleccion ambito.jsp? IDIOMA=en

INE. Census 2001.Retrieved 3/09/2016 from:

http://www.ine.es/en/censo2001/index_en.html

INE. Census 2011. Retrieved 11/08/2016 from:

http://www.ine.es/en/censos2011_datos/cen11_datos_inicio_en.htm

Jo, H. K., Han, I. G., \& Lee, H. Y. (1997). Bankruptcy prediction using case-based reasoning, neural networks, and discriminant analysis. EXPERT SYSTEMS WITH APPLICATIONS, 13(2), 97-108. article. http://doi.org/10.1016/S09574174(97)00011-0

Khalil, N., Kamaruzzaman, S. N., \& Baharum, M. R. (2016). Ranking the indicators of building performance and the users' risk via Analytical Hierarchy Process (AHP): Case of Malaysia. Ecological Indicators, 71, 567-576. article. http://doi.org/10.1016/j.ecolind.2016.07.032 
Kaplan, S., \& Garrick, B. J. (1981). On The Quantitative Definition of Risk. Risk Analysis, 1(1), 11-27. article. http://doi.org/10.1111/j.1539-6924.1981.tb01350.x

Karagiorgos, K., Thaler, T., Heiser, M., Hübl, J., \& Fuchs, S. (2016). Integrated flash flood vulnerability assessment: Insights from East Attica, Greece. Journal of Hydrology. article. http://doi.org/10.1016/j.jhydrol.2016.02.052

King, R. A. R., \& Blackmore, K. L. (2013). Physical and political boundaries as barriers to the continuity of social vulnerability. Applied Geography, 44, 79-87. http://doi.org/http://dx.doi.org/10.1016/j.apgeog.2013.07.011

Kotzee, I., \& Reyers, B. (2016). Piloting a social-ecological index for measuring flood resilience: A composite index approach. Ecological Indicators, 60, 45-53. http://doi.org/10.1016/j.ecolind.2015.06.018

Kubler, S., Robert, J., Derigent, W., Voisin, A., \& Le Traon, Y. (2016). A state-of theart survey \& testbed of fuzzy AHP (FAHP) applications. Expert Systems with Applications, 65, 398-422. article. http://doi.org/10.1016/j.eswa.2016.08.064

Leong, Y. T., Lee, J.-Y., Tan, R. R., Foo, J. J., \& Chew, I. M. L. (2017). Multi-objective optimization for resource network synthesis in eco-industrial parks using an integrated analytic hierarchy process. JOURNAL OF CLEANER PRODUCTION, 143, 1268-1283. article. http://doi.org/10.1016/j.jclepro.2016.11.147

Liu, Y., Chen, J., He, W., Tong, Q., \& Li, W. (2010). Application of an Uncertainty Analysis Approach to Strategic Environmental Assessment for Urban Planning. Environmental Science \& Technology, 44(8), 3136-3141.

Lummen, N. S., \& Yamada, F. (2014). Implementation of an integrated vulnerability and risk assessment model. Natural Hazards, 73(2), 1085-1117. http://doi.org/10.1007/s11069-014-1123-6 
Malekpour, S., Brown, R. R., \& de Haan, F. J. (2015). Strategic planning of urban infrastructure for environmental sustainability: Understanding the past to intervene for the future. Cities, 46, 67-75.

Malley, J. D., Kruppa, J., Dasgupta, A., Malley, K. G., \& Ziegler, A. (2012). Probability Machines Consistent Probability Estimation Using Nonparametric Learning Machines. METHODS OF INFORMATION IN MEDICINE, 51(1), 74-81. article. http://doi.org/10.3414/ME00-01-0052

Marozzi, M. (2016). Construction, Robustness Assessment and Application of an Index of Perceived Level of Socio-Economic Threat from Immigrants: A Study of 47 European Countries and Regions. SOCIAL INDICATORS RESEARCH, 128(1), 413-437. article. http://doi.org/10.1007/s11205-015-1037-z

Martí, J. V, García-Segura, T., \& Yepes, V. (2016). Structural design of precastprestressed concrete U-beam road bridges based on embodied energy. Journal of Cleaner Production, 120, 231-240. article.

http://doi.org/http://doi.org/10.1016/j.jclepro.2016.02.024

McCarthy, J.J., O.F. Canziani, N.A. Leary, D. J. D. and K. S., \& (eds), W. (2001). Climate change 2001: impacts, adaptation, and vulnerability. Cambridge University Press, Cambridge.

Mi, Z.-F., Wei, Y.-M., Tang, B.-J., Cong, R.-G., Yu, H., Cao, H., \& Guan, D. (2017). Risk assessment of oil price from static and dynamic modelling approaches. APPLIED ECONOMICS, 49(9), 929-939. article. http://doi.org/10.1080/00036846.2016.1208359

Mousavi-Avval, S. H., Rafiee, S., Sharifi, M., Hosseinpour, S., Notarnicola, B., Tassielli, G., \& Renzulli, P. A. (2017). Application of multi-objective genetic algorithms for optimization of energy, economics and environmental life cycle assessment in oilseed production. JOURNAL OF CLEANER PRODUCTION, 140(2, SI), 804-815. article. http://doi.org/10.1016/j.jclepro.2016.03.075

Munda, G. (2004). Social multi-criteria evaluation: Methodological foundations and operational consequences. European Journal of Operational Research, 158(3), 662-677. http://doi.org/10.1016/S0377-2217(03)00369-2 
Mustafa, D., Ahmed, S., Saroch, E., \& Bell, H. (2011). Pinning down vulnerability: from narratives to numbers. Disasters, 35(1), 62-86. http://doi.org/10.1111/j.03613666.2010.01193.x

Mzolo, T., Goris, G., Talens, E., Bucchianico, A. D., \& Heuvel, E. V. D. (2015). Statistical Process Control Methods for Monitoring In-House Reference Standards. Statistics in Biopharmaceutical Research, 7(1), 55-65. article. http://doi.org/10.1080/19466315.2015.1004271

Nahiduzzaman, K. M., Aldosary, A. S., \& Rahman, M. T. (2015). Flood induced vulnerability in strategic plan making process of Riyadh city. Habitat International, 49, 375-385. http://doi.org/10.1016/j.habitatint.2015.05.034

Nielsen, L. S., Lindholst, C., \& Villesen, P. (2016). Cocaine classification using alkaloid and residual solvent profiling. FORENSIC SCIENCE INTERNATIONAL, 269, 42-49. article. http://doi.org/10.1016/j.forsciint.2016.11.007

Observatorio de Vulnerabilidad Urbana, (2010) Análisis urbanístico de barrios vulnerables. Retrieved 08/26/2015 from:

https://www.fomento.gob.es/MFOM/LANG_CASTELLANO/DIRECCIONES_GENE RALES/ARQ_VIVIENDA/SUELO_Y_POLITICAS/OBSERVATORIO/Analisis_urba _Barrios_Vulnerables/Informes_CCAA.htm

Pamungkas, A., Bekessy, S. A., \& Lane, R. (2014). Vulnerability Modelling to Improve Assessment Process on Community Vulnerability. Procedia Social and Behavioral Sciences, 135, 159-166. http://doi.org/10.1016/j.sbspro.2014.07.341

Parvizimosaed, M., Farmani, F., Monsef, H., \& Rahimi-Kian, A. (2017). A multi-stage Smart Energy Management System under multiple uncertainties: A data mining approach. RENEWABLE ENERGY, 102(A), 178-189. article. http://doi.org/10.1016/j.renene.2016.10.021

Pellicer, E., Sierra, L. A., \& Yepes, V. (2016). Appraisal of infrastructure sustainability by graduate students using an active-learning method. Journal of Cleaner Production, 113, 884-896. article. http://doi.org/http://doi.org/10.1016/j.jclepro.2015.11.010

Pemberton, S., \& Searle, G. (2016). Statecraft, Scalecraft and Urban Planning: A Comparative Study of Birmingham, UK, and Brisbane, Australia. EUROPEAN 
PLANNING STUDIES, 24(1), 76-95.

http://doi.org/10.1080/09654313.2015.1078297

Penades-Pla, V., Garcia-Segura, T., Marti, J. V, \& Yepes, V. (2016). A Review of Multi-Criteria Decision-Making Methods Applied to the Sustainable Bridge Design. SUSTAINABILITY, 8(12). article. http://doi.org/10.3390/su8121295

Rigillo, M., \& Cervelli, E. (2014). Mapping Urban Vulnerability: the Case Study of Gran Santo Domingo, Dominican Republic. Advanced Engineering Forum, 11, 142-148. http://doi.org/10.4028/www.scientific.net/AEF.11.142

Romero Lankao, P., \& Qin, H. (2011). Conceptualizing urban vulnerability to global climate and environmental change. Current Opinion in Environmental Sustainability, 3(3), 142-149. http://doi.org/10.1016/j.cosust.2010.12.016

Saaty, t. 1. (1990). How to make a decision - the analytic hierarchy process. European Journal of Operational Research, 48(1), 9-26. article. http://doi.org/10.1016/03772217(90)90057-I

Shen, L., Jiang, S., \& Yuan, H. (2012). Critical indicators for assessing the contribution of infrastructure projects to coordinated urban-rural development in China. Habitat International, 36(2), 237-246. JOUR. http://doi.org/http://dx.doi.org/10.1016/j.habitatint.2011.10.003

Solín, L. (2012). Spatial variability in the flood vulnerability of urban areas in the headwater basins of Slovakia. Journal of Flood Risk Management, 5(4), 303-320. http://doi.org/10.1111/j.1753-318X.2012.01153.x

Stern, P. C., Ebi, K. L., Leichenko, R., Olson, R. S., Steinbruner, J. D., \& Lempert, R. (2013). Managing risk with climate vulnerability science. Nature Climate Change, 3(7), 607-609. http://doi.org/10.1038/nclimate1929

Torres-Machi, C., Pellicer, E., Yepes, V., \& Chamorro, A. (2017). Towards a sustainable optimization of pavement maintenance programs under budgetary restrictions. Journal of Cleaner Production, 148, 90-102. article. http://doi.org/http://doi.org/10.1016/j.jclepro.2017.01.100

Toubin, M., Laganier, R., Diab, Y., \& Serre, D. (2015). Improving the Conditions for Urban Resilience through Collaborative Learning of Parisian Urban Services. 
JOURNAL OF URBAN PLANNING AND DEVELOPMENT, 141(4).

http://doi.org/10.1061/(ASCE)UP.1943-5444.0000229

Turner, B. L., Kasperson, R. E., Matson, P. A., McCarthy, J. J., Corell, R. W., Christensen, L., et al. (2003). A framework for vulnerability analysis in sustainability science. Proceedings of the National Academy of Sciences of the United States of America, 100(14), 8074-8079. http://doi.org/10.1073/pnas.1231335100

Villa, V., Paltrinieri, N., Khan, F., \& Cozzani, V. (2016). Towards dynamic risk analysis: A review of the risk assessment approach and its limitations in the chemical process industry. SAFETY SCIENCE, 89, 77-93. article. http://doi.org/10.1016/j.ssci.2016.06.002

Wolf, S., Hinkel, J., Hallier, M., Bisaro, A., Lincke, D., Ionescu, C., \& Klein, R. J. T. (2013). Clarifying vulnerability definitions and assessments using formalisation. International Journal of Climate Change Strategies and Management, 5(1), 54-70. http://doi.org/10.1108/17568691311299363

Yepes, V., García-Segura, T., \& Moreno-Jiménez, J. M. (2015). A cognitive approach for the multi-objective optimization of RC structural problems. Archives of Civil and Mechanical Engineering, 15(4), 1024-1036. http://doi.org/10.1016/j.acme.2015.05.001

Zamarrón-Mieza, I., Yepes, V., \& Moreno-Jiménez, J. M. (2017). A systematic review of application of multi-criteria decision analysis for aging-dam management. Journal of Cleaner Production, 147, 217-230. article. http://doi.org/http://doi.org/10.1016/j.jclepro.2017.01.092

Zhang, R., \& Chiong, R. (2016). Solving the energy-efficient job shop scheduling problem: a multi-objective genetic algorithm with enhanced local search for minimizing the total weighted tardiness and total energy consumption. JOURNAL OF CLEANER PRODUCTION, 112(4), 3361-3375. article. http://doi.org/10.1016/j.jclepro.2015.09.097

Zhou, A., Qu, B.-Y., Li, H., Zhao, S.-Z., Suganthan, P. N., \& Zhangd, Q. (2011). Multiobjective evolutionary algorithms: A survey of the state of the art. Swarm and Evolutionary Computation, 1(1), 32-49. JOUR. http://doi.org/10.1016/j.swevo.2011.03.001 
p. 29 of 36 
Table 1. Results of the AHP process and of the best model for each decision objective:

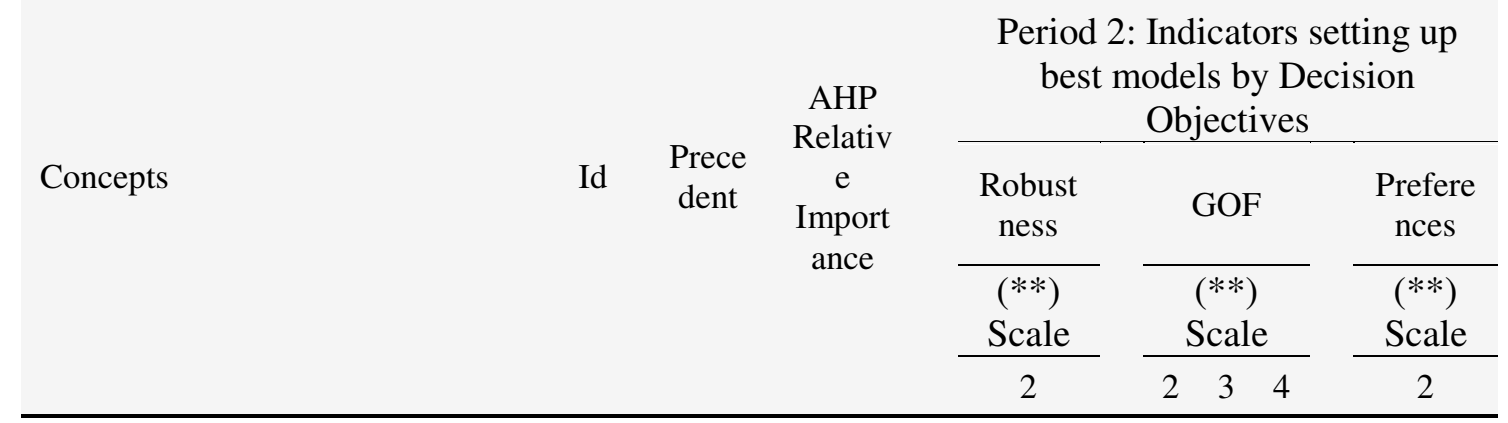

Approaches:

Socio-Economic

$\mathrm{SE} \quad-\quad 51,81$

Biophysical

$\begin{array}{lll}\text { A } & - & 48,19\end{array}$

\begin{tabular}{|c|c|c|c|}
\hline \multicolumn{4}{|l|}{ Aspects: } \\
\hline Social structure & $\begin{array}{c}\text { SST } \\
\text { R }\end{array}$ & & 27,68 \\
\hline Population Activity level & $\begin{array}{l}\mathrm{PA} \\
\mathrm{CT}\end{array}$ & SEA & 11,49 \\
\hline Population Educational level & $\begin{array}{l}\mathrm{PE} \\
\mathrm{DU}\end{array}$ & & 12,64 \\
\hline Area occupation & $\begin{array}{l}\mathrm{AO} \\
\mathrm{CC}\end{array}$ & & 9,6 \\
\hline Dwellings condition & $\begin{array}{l}\mathrm{DC} \\
\mathrm{ON}\end{array}$ & & 11,75 \\
\hline Dwellings size & $\begin{array}{c}\text { DSI } \\
\text { Z }\end{array}$ & BA & 16,37 \\
\hline Dwellings usage & $\begin{array}{l}\text { DU } \\
\text { SA }\end{array}$ & & 5,63 \\
\hline Dwellings age & $\begin{array}{l}\mathrm{DA} \\
\mathrm{GE}\end{array}$ & & 4,84 \\
\hline
\end{tabular}

\begin{tabular}{|c|c|c|c|c|c|c|c|c|}
\hline Indicators: & & & & & & & & \\
\hline Area Population & 1 & \multirow{5}{*}{ SSTR } & 3,64 & 0 & 1 & 1 & 1 & 1 \\
\hline Population density (pop/ha) & 2 & & 8,84 & 1 & 1 & 1 & 1 & 1 \\
\hline Eder 75 years or more $(\%)$ & 3 & & 5,85 & 1 & 1 & 1 & 0 & 1 \\
\hline $\begin{array}{l}\text { Households of one person } \\
\text { older than } 64 \text { years }(\%)\end{array}$ & 4 & & 3,68 & 0 & 1 & 0 & 1 & 1 \\
\hline $\begin{array}{l}\text { Households of one adult and at } \\
\text { least one minor }(\%)\end{array}$ & 5 & & 5,67 & 1 & 1 & 1 & 1 & 1 \\
\hline $\begin{array}{l}\text { (\%) BI-1: Unemployment rate } \\
(\%)\end{array}$ & 6 & \multirow{4}{*}{ PACT } & 4,47 & 1 & 1 & 1 & 1 & 1 \\
\hline Youth unemployment rate $(\%)$ & 7 & & 1,99 & 1 & 1 & 1 & 1 & 1 \\
\hline Tempory employee(\%) & 8 & & 2,02 & 0 & 1 & 0 & 0 & 1 \\
\hline Unqualified workers (\%) & 9 & & 3 & 1 & 1 & 1 & 1 & 1 \\
\hline $\begin{array}{l}\text { (*) NI-2. Population } \\
\text { uneducated }(\%)\end{array}$ & 10 & \multirow{4}{*}{ PED } & 4,24 & 1 & 1 & 1 & 0 & 1 \\
\hline $\begin{array}{l}\text { Population with primary } \\
\text { education }(\%)\end{array}$ & 11 & & 3,8 & 0 & 1 & 1 & 1 & 1 \\
\hline $\begin{array}{l}\text { Population with secondary } \\
\text { education }(\%)\end{array}$ & 12 & & 1,75 & 1 & 1 & 0 & 1 & 1 \\
\hline $\begin{array}{l}\text { Population with higher } \\
\text { education }(\%)\end{array}$ & 13 & & 2,85 & 0 & 1 & 1 & 1 & 1 \\
\hline
\end{tabular}




\begin{tabular}{|c|c|c|c|c|c|c|c|c|}
\hline Number of dwellings(u) & 14 & \multirow{3}{*}{$\begin{array}{c}\mathrm{AOC} \\
\mathrm{C}\end{array}$} & 1,65 & 1 & 1 & 1 & 0 & 1 \\
\hline Dwellings density $(\mathrm{u} / \mathrm{Ha})$ & 15 & & 6,15 & 0 & 1 & 1 & 1 & 1 \\
\hline Area $(\mathrm{Ha})$ & 16 & & 1,8 & 1 & 1 & 1 & 1 & 1 \\
\hline (*) BI-3: Dwellings rate (\% & 17 & \multirow{7}{*}{$\begin{array}{l}\text { DCO } \\
\mathrm{N}\end{array}$} & 1,05 & & & & & \\
\hline $\begin{array}{l}\text { Population with no WC in } \\
\text { the dwelling) }\end{array}$ & & & & 1 & 1 & 1 & 1 & 1 \\
\hline $\begin{array}{l}\text { Dwellings in ruin condition } \\
(\%)\end{array}$ & 18 & & 3,4 & 0 & 0 & 1 & 1 & 1 \\
\hline Dwellings in bad condition (\%) & 19 & & 2,6 & 0 & 1 & 0 & 0 & 1 \\
\hline $\begin{array}{l}\text { Dwellings in deficient } \\
\text { condition }(\%)\end{array}$ & 20 & & 1,77 & 1 & 1 & 0 & 0 & 1 \\
\hline $\begin{array}{l}\text { Dwellings in good condition } \\
(\%)\end{array}$ & 21 & & 1,29 & 0 & 1 & 1 & 1 & 1 \\
\hline $\begin{array}{l}\text { Dwellings without running } \\
\text { water }(\%)\end{array}$ & 22 & & 1,64 & 1 & 1 & 1 & 1 & 1 \\
\hline $\begin{array}{l}\text { Dwellings with less than } 30 \\
\mathrm{~m} 2(\%)\end{array}$ & 23 & \multirow{5}{*}{ DSIZ } & 2,75 & 0 & 1 & 0 & 0 & 1 \\
\hline $\begin{array}{l}\text { Dwellings total usable surface } \\
(\mathrm{m} 2)\end{array}$ & 24 & & 2,5 & 0 & 0 & 0 & 0 & 0 \\
\hline $\begin{array}{l}\text { Mean usable surface by } \\
\text { dwelling (m2) }\end{array}$ & 25 & & 3,88 & 0 & 0 & 0 & 1 & 0 \\
\hline $\begin{array}{l}\text { Mean usable surface by } \\
\text { habitant }(\mathrm{m} 2)\end{array}$ & 26 & & 3,44 & 0 & 1 & 1 & 1 & 1 \\
\hline $\begin{array}{l}\text { Number of rooms by dwelling } \\
\text { (u/dwell) }\end{array}$ & 27 & & 3,8 & 1 & 1 & 1 & 1 & 1 \\
\hline Main Dwellings (u) & 28 & \multirow{4}{*}{$\begin{array}{c}\text { DUS } \\
\text { A }\end{array}$} & 1,05 & 1 & 1 & 1 & 1 & 1 \\
\hline Empty Dwellings (u) & 29 & & 2,34 & 1 & 1 & 1 & 1 & 1 \\
\hline Owned Dwellings (u) & 30 & & 0,76 & 0 & 1 & 1 & 0 & 1 \\
\hline Rented Dwellings (u) & 31 & & 1,48 & 0 & 1 & 1 & 1 & 1 \\
\hline $\begin{array}{l}\text { Dwellings in buildgs built } \\
\text { before } 1951(\%)\end{array}$ & 32 & \multirow{5}{*}{$\begin{array}{l}\text { DAG } \\
\text { E }\end{array}$} & $1,49^{-}$ & 1 & 0 & 0 & 0 & 1 \\
\hline Total buldings (u) & 33 & & 0,44 & 1 & 0 & 1 & 1 & 1 \\
\hline $\begin{array}{l}\text { Buildings older than } 30 \text { years } \\
\text { (u) } \\
\text { Buildings older than } 50 \text { years }\end{array}$ & $\begin{array}{l}34 \\
35\end{array}$ & & $\begin{array}{l}0,51 \\
1,45\end{array}$ & 0 & 1 & 1 & 1 & 1 \\
\hline (u) & & & \multirow[b]{2}{*}{0,96} & 1 & 1 & 1 & 1 & 1 \\
\hline $\begin{array}{l}\text { Buildings older than } 80 \text { years } \\
\text { (u) }\end{array}$ & 36 & & & 0 & 1 & 0 & 0 & 0 \\
\hline $\begin{array}{l}\text { (*) Criteria selected for the basic } \\
\text { UVA framework } \\
\text { (**) Scales: } 2=\text { City; } 3= \\
\text { Province; } 4 \text { = Region. }\end{array}$ & & & up the & & & & & \\
\hline
\end{tabular}


Table 2: Objectives describing behaviour and comparative between optimizations with and without breaking down the GOF objective

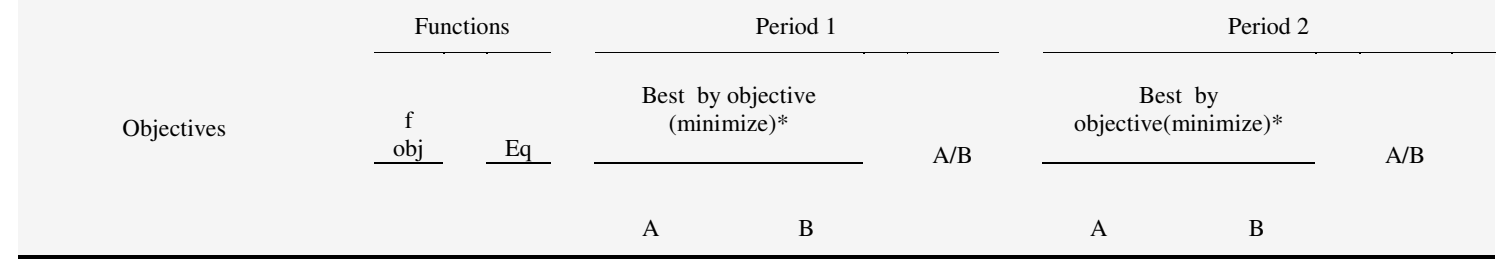

\section{Decision Objectives:}

\begin{tabular}{lllllllll} 
Preferences & 1 & 1 & $-0,953$ & $-0,95$ & 1,003 & $-0,957$ & $-0,913$ & 1,048 \\
Robustness & 2 & 2 & -67.213 & -79.776 & 0,843 & -21.184 & -21.405 & 0,990 \\
GOF Overall & 3 & 4 & $-2,243$ & $-2,32$ & 0,967 & $-1,696$ & $-1,879$ & 0,903 \\
\hline
\end{tabular}

\section{Control Objectives:}

\begin{tabular}{|c|c|c|c|c|c|c|c|}
\hline Multi-Scale Simirarity & 4 & 6 & $-0,048$ & $-0,037$ & 1,297 & $-0,108$ & $-0,065$ \\
\hline Time Dynamics & 4 & 5 & & & & $-2,989$ & $-2,989$ \\
\hline GOF scale 1: Neighborhood & 5 & 3 & & $-0,08$ & & & \\
\hline GOF scale 2: City & 6 & 3 & & $-0,25$ & & & $-0,303$ \\
\hline GOF scale 3: Province & 7 & 3 & & -1 & & & $-0,674$ \\
\hline GOF scale 4: Region & 8 & 3 & & -1 & & & $-1,000$ \\
\hline
\end{tabular}

A:GOF represented by 1 overall objective

B: GOF represented by 1 overall objective and independient objectives by scale

(*) Compriomise solutions after 500 iterations and a population of 300 individuals 


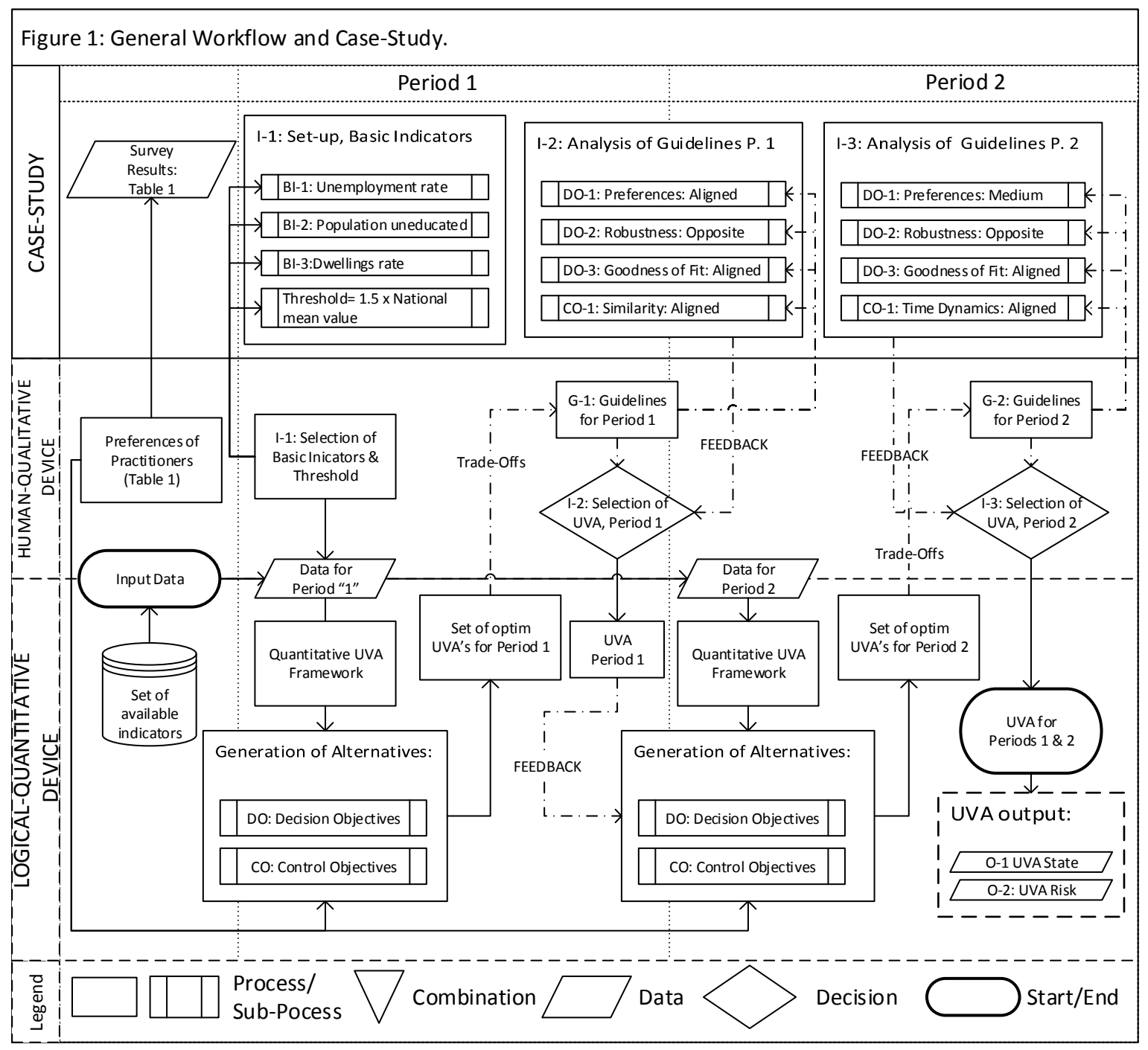

Fig. 1. Figure 1: Method for selecting UVA models, General Workflow and Case-Study. 


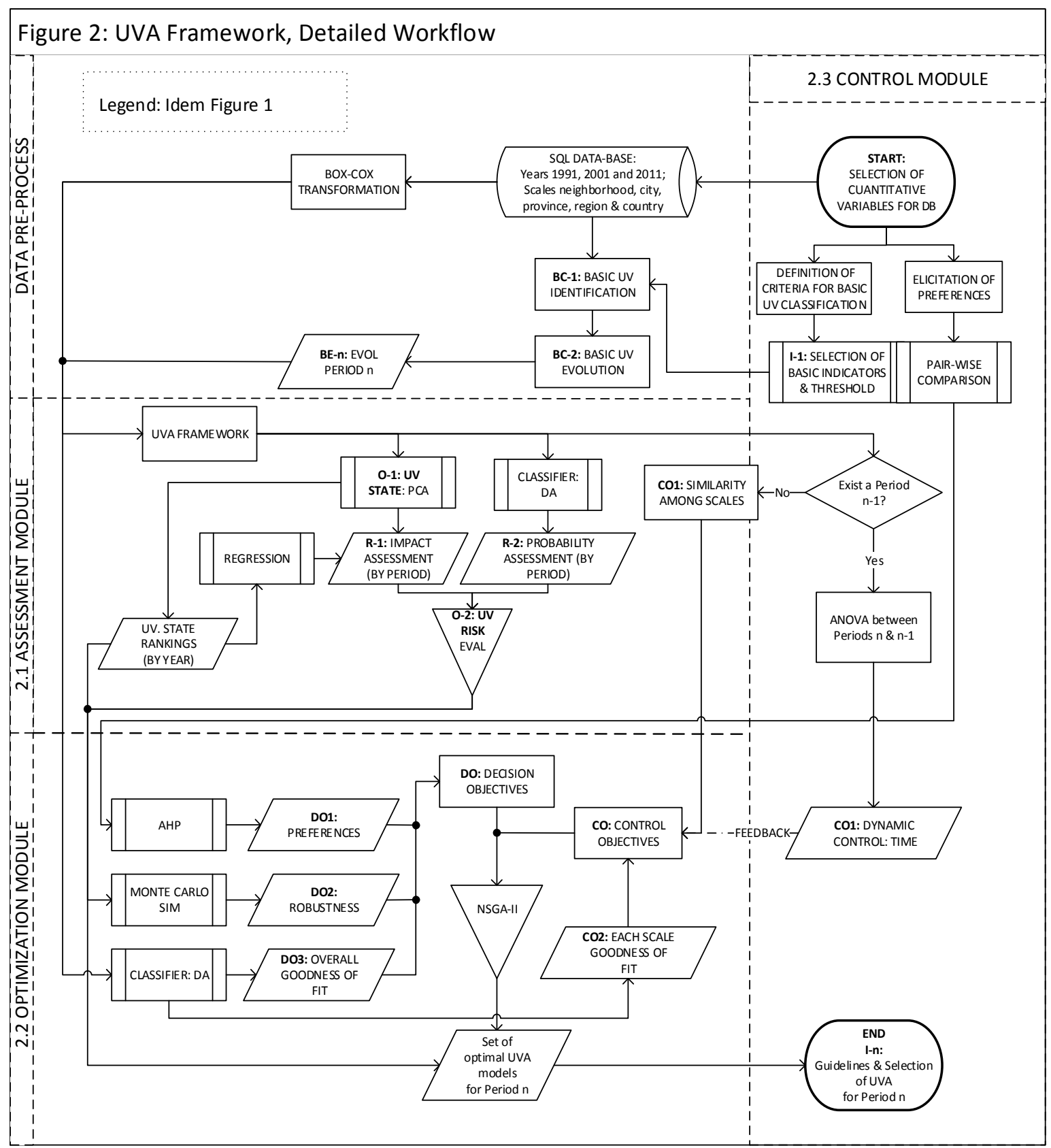

Fig. 2. Figure 2: UVA Framework, Detailed Workflow 


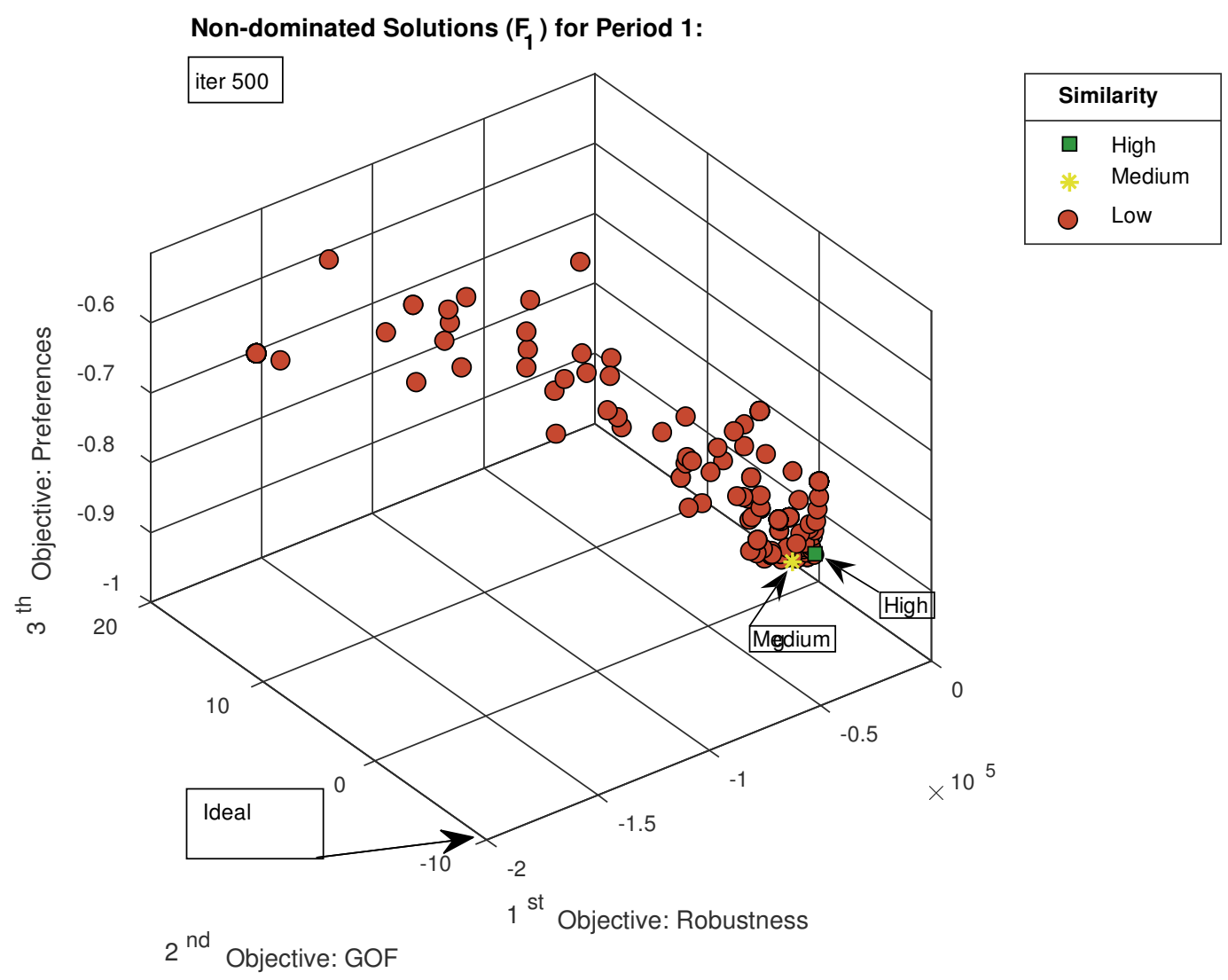

Fig. 3. Set of compromise solutions for period 1 .

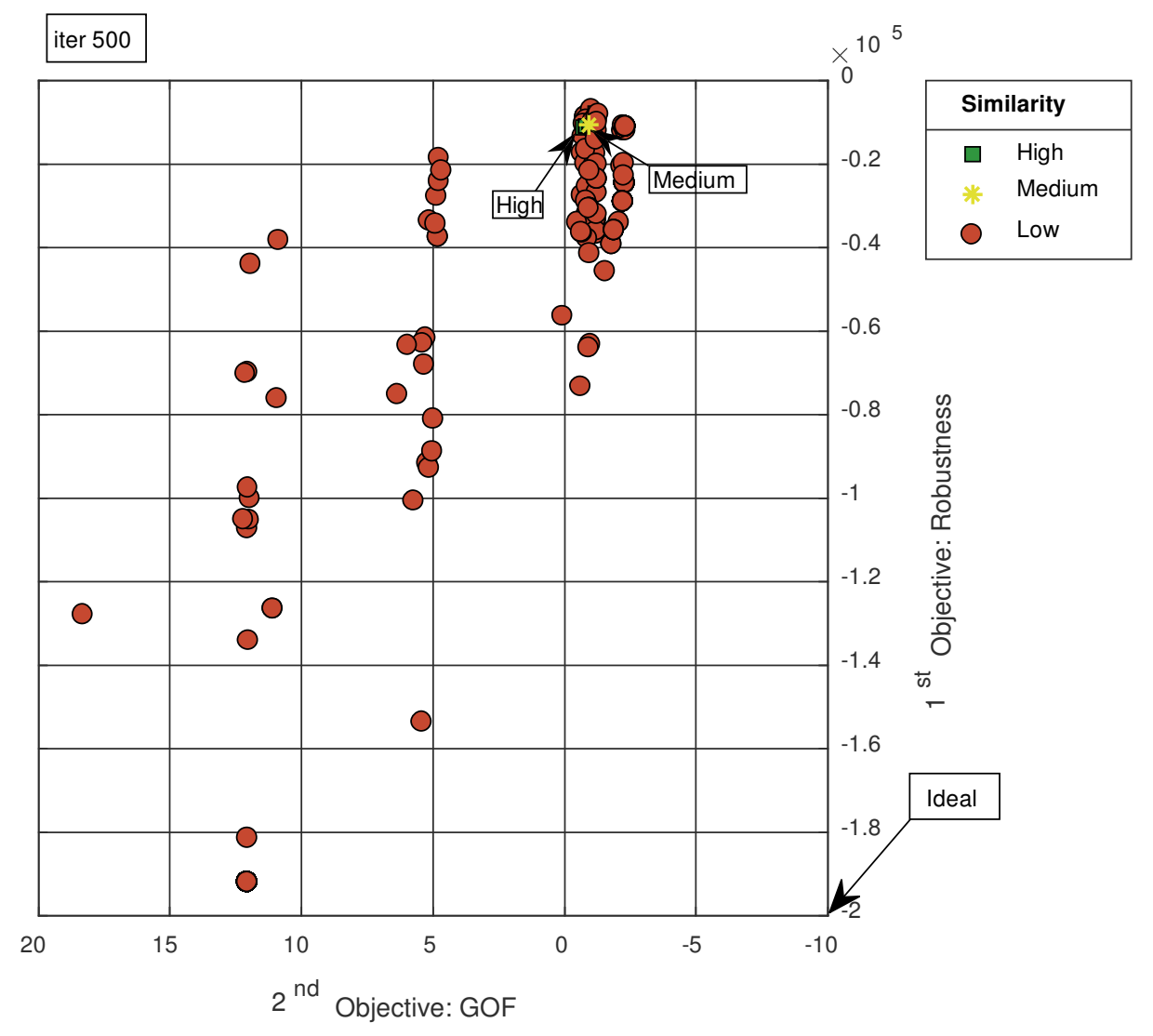

Fig. 4. Trade-off between Robustness and GOF for period 1. 


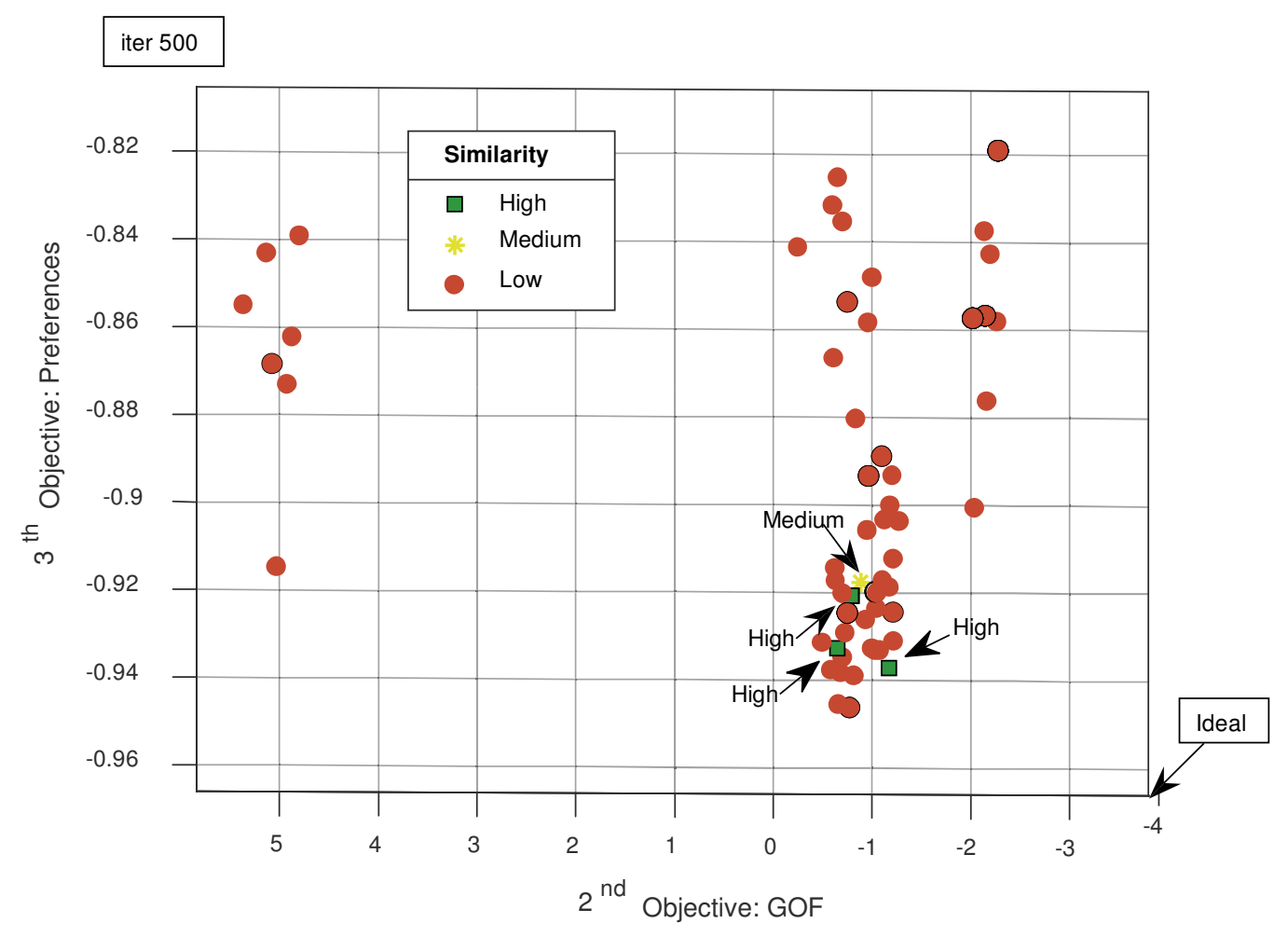

Fig. 5. Trade-off between GOF and preferences for period 1 .

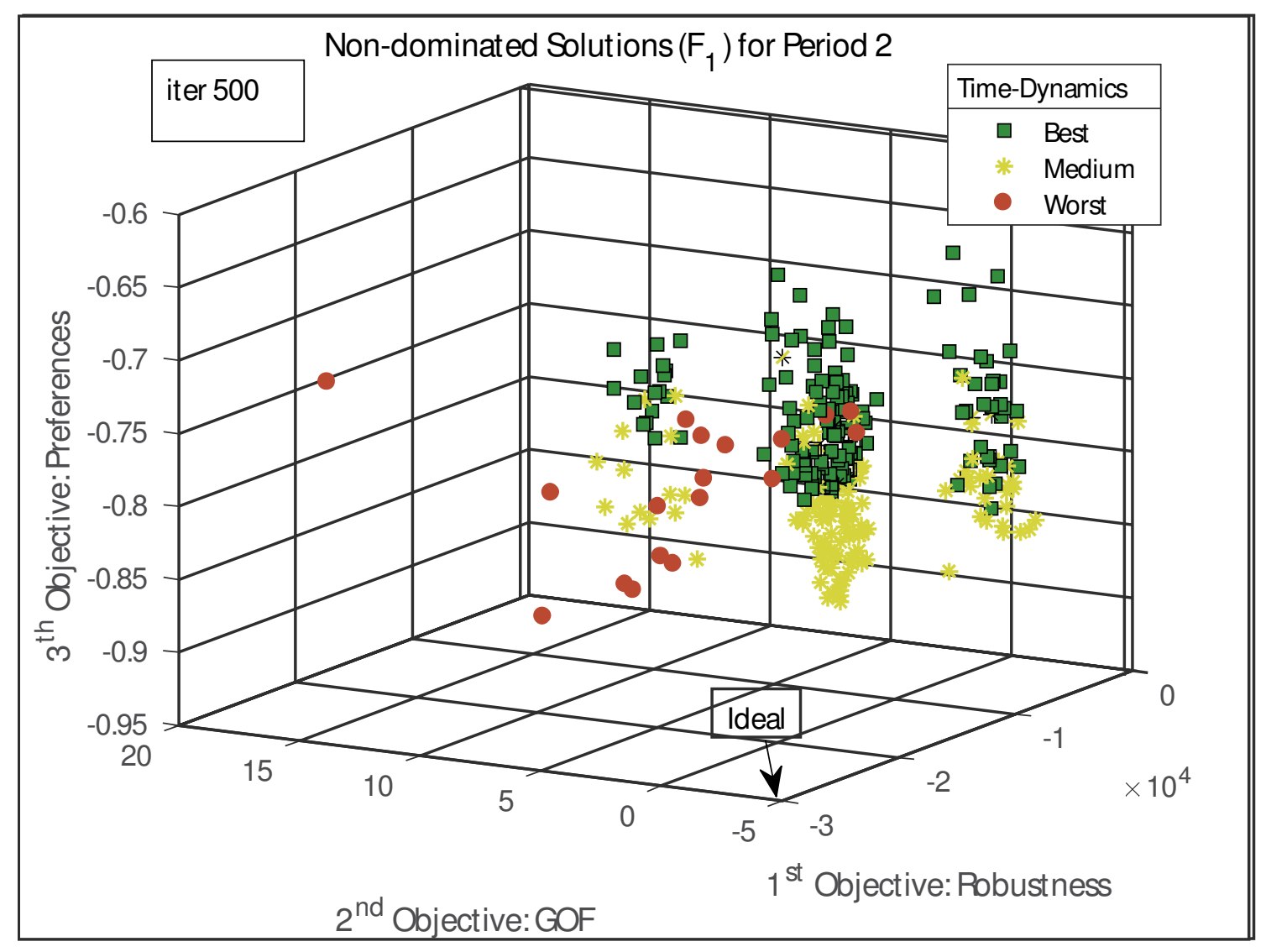

Fig. 6. Compromise solutions for period 2 . 